\title{
Concepções de famílias: Um estudo sobre as representações gráficas de crianças cariocas
}

\section{Conceptions of Families: A study on the graphic representations of children from Rio de Janeiro}

\section{Concepciones de Familias: Un estudio sobre las representaciones gráficas de niños cariocas}

\author{
Ilana Landim* \\ Pontifícia Universidade Católica do Rio de Janeiro - PUC-Rio, Rio de Janeiro, Rio de \\ Janeiro, Brasil
}

Juliane Callegaro Borsa**

Pontifícia Universidade Católica do Rio de Janeiro - PUC-Rio, Rio de Janeiro, Rio de Janeiro, Brasil

\begin{abstract}
RESUMO
As configurações familiares estão em processo de diversificação, de maneira que o modelo formado por homem e mulher unidos em matrimônio não é o único a ser legitimado pela sociedade. Este estudo objetivou investigar de que forma as crianças cariocas representam graficamente as famílias, tomando como base a teoria da análise do comportamento. Participaram da amostra 108 crianças cariocas (52,8\% meninos e $47,2 \%$ meninas), com idades entre cinco e 12 anos $(M=8,58 ; D P=1,54)$ e seus respectivos responsáveis $(M=36,9 ; D P=7,31)$. Foi solicitado que as crianças desenhassem individualmente uma família e a descrevessem. Aos responsáveis foi pedido que preenchessem um questionário sociodemográfico. Os conteúdos dos desenhos e os dados do questionário sociodemográfico foram tabulados e analisados por meio do software estatístico IBM SPSS versão 22. A maior parte das crianças representou famílias tradicionais em seus desenhos. No entanto, as concepções de família pareceram mais associadas à dimensão afetiva que aos espaços de convivência e moradia. Esse estudo propôs novas perspectivas empíricas e teóricas para avaliar o desenho da família e sugere a necessidade de melhor compreender como os diversos arranjos familiares são apreendidos pelas crianças.
\end{abstract}

Palavras-chaves: famílias, desenho de família, criança.

\section{ABSTRACT}

The family configurations are in the process of diversification, so that the model formed by man and woman united in matrimony is not the only one to be legitimized by society. This study aimed to investigate how the Carioca children graphically represent families, based on the theory of behavior analysis. A total of 108 carioca children ( $52.8 \%$ boys and $47,2 \%$ girls), aged between five and 12 years $(M=8.58, D P=1.54)$ and their respective 
parents $(M=36.9$ males; $D P=7.31)$. The children were asked to design individually a family and describe it. Respondents were asked to complete a sociodemographic questionnaire. The contents of the drawings and data of the sociodemographic questionnaire were tabulated and analyzed using the statistical software IBM SPSS version 22. Most of the children represented traditional families in their designs. However, the conceptions of family seemed more associated to the affective dimension than to the spaces of coexistence and dwelling. This study proposed new empirical and theoretical perspectives to evaluate the family drawing and suggests the need to better understand how the various family arrangements are apprehended by the children.

Keywords: families, family drawing, child.

\section{RESUMEN}

Los arreglos familiares están en proceso de diversificación, de modo que el modelo formado por hombre y mujer unidos en matrimonio no es el único a ser legitimado por la sociedad. Este estudio busca investigar de qué forma los niños cariocas representan gráficamente a las familias, tomando por base la teoría del análisis del comportamiento. Participaron del estudio 108 niños cariocas ( $52,8 \%$ ninos y $47,2 \%$ niñas), con edades entre cinco y 12 años ( $M$ $=8,58, D P=1,54)$ y sus respectivos responsables $(M$ edad $=36,9, D P=$ $7,31)$. Se solicitó a los niños que dibujaran individualmente una familia y la describieran, y se pidió a los responsables el llenado de un cuestionario sociodemográfico. Los contenidos de los dibujos y los datos del cuestionario sociodemográfico fueron tabulados y analizados a través del software estadístico IBM SPSS versión 22. La mayoría de los niños representó familias tradicionales en sus dibujos. Sin embargo, las concepciones de familia parecían más asociadas a la dimensión afectiva que a los espacios de convivencia y vivienda. Este estudio propone nuevas perspectivas empíricas y teóricas para evaluar el diseño de la familia y sugiere la necesidad de comprender mejor cómo los diversas padrones familiares son asimilados por los niños.

Palabras claves: familias, diseño de familia, niño.

Historicamente, o conceito de família vem sendo associado à união de um homem e uma mulher em matrimônio com a finalidade de procriação. Porém, as famílias tiveram que modificar sua constituição para abarcar as novas exigências culturais, como a necessidade de uma maior participação da mulher em outros espaços que não se restringiam ao lar, o compartilhamento de papéis entre homens e mulheres, a legitimação de famílias formadas por apenas um genitor e filhos, entre outros (Dias, 2017).

A análise do comportamento, abordagem de escolha deste estudo, considera as famílias conforme as transformações sociais do ambiente em que estão inseridas. As famílias são compreendidas como sistemas complexos, em constante interação com o ambiente, transformando e sendo transformadas por essa relação (Figueiredo \& Naves, 2018; Skinner, 2003/1953). Trata-se de sistemas interligados e influenciados pelo âmbito cultural. Tiveram que modificar o seu funcionamento para abarcar as novas exigências culturais, como a de 
que crianças e seu desenvolvimento humano deveriam ser o foco da família moderna. Nesse sentido, famílias se caracterizam como agências controladoras do comportamento humano ao informar como o indivíduo deve se comportar para não ser punido ou excluído de outras instituições ou agências (Naves \& Vasconcelos, 2008; Skinner, 2003/1953). Famílias se revelam, mesmo que influenciadas por outras agências de controle (mídia, economia, religião, educacional, entre outras), como a primeira instituição a validar para crianças noções de certo e errado, ganhos e perdas, adequados e inadequados, reproduzidas por outras agências (Et \& Memis, 2017; Skinner, 2003/1953).

As concepções teóricas, como a análise do comportamento, vêm contribuindo para a compreensão de famílias e diversas configurações familiares (Silva \& Avelar, 2014). Existem alguns estudos indicando como crianças caracterizam famílias em periódicos (Ribeiro \& Cruz, 2013; Silva \& Avelar, 2014). No entanto, apesar do crescimento de pesquisas sobre a temática, ainda há um entendimento limitado sobre como as crianças compreendem as diferentes e novas configurações familiares. Compreender como a diversificação de família é percebida pelas crianças pode influenciar a atuação do psicólogo e pesquisador que intervém em grupos familiares (Naves \& Vasconcelos, 2008). Além disso, a maneira como interpretam e se relacionam com famílias pode influenciar no desenvolvimento humano (Bijou \& Latham, 2012; Rigg \& Pryor, 2007). Isso se deve ao fato de que as famílias exercem um papel relevante nos processos de individualização na medida em que interagem com a criança e demonstram possibilidades de como ela pode se comportar em relação ao ambiente, indo ao encontro da conceituação defendida pela análise do comportamento de família como agência de controle (Silva \& Avelar, 2014).

Uma das justificativas para a falta de pesquisas com crianças tem relação com sua falta de recursos verbais quando comparadas aos adultos (Regra, 2001). Para tanto, as técnicas gráficas configuram-se como ferramentas úteis para a compreensão de sentimentos e pensamentos (Figueiredo \& Naves, 2018). As crianças encontram no desenho a possibilidade de comunicar o que ainda não conseguem verbalizar (Regra, 2001). Para a análise do comportamento, o indivíduo pode reportar, por meio do desenho, como observa o seu ambiente, sem que esteja presencialmente nele ou sem que racionalize sobre ele. Podem estar presentes junto ao comportamento de desenhar, os comportamentos de pensar e sentir. Enquanto o indivíduo é convidado a desenhar, também é incitado a falar de maneira privada (pensar) e a realizar indiretamente uma análise sobre a função de sentimentos e pensamentos (Figueiredo \& Naves, 2018). A representação gráfica de famílias é uma das modalidades de desenho relevante na prática e pesquisa com crianças sobre 
percepções de famílias (Ribeiro \& Cruz, 2013; Silva \& Avelar, 2014). O desenho da família, por exemplo, permite compreender como o indivíduo concebe e define a família em termos de funções, laços e relações de poder (Wagner \& Bandeira, 1996; Wagner \& FéresCarneiro, 2000). O presente estudo teve como objetivo investigar de que forma as crianças cariocas representam graficamente as famílias, tomando como base a teoria da análise do comportamento (Figueiredo \& Naves, 2018; Regra, 2001; Skinner, 2003/1953).

\section{Método}

\section{Participantes}

Participaram da amostra 108 crianças, com idades entre cinco e 12 anos $(M=8,58 ; D P=1,54)$, residentes na cidade do Rio de Janeiro (RJ), sendo 51 meninas $(47,2 \%)$ e 57 meninos $(52,8 \%)$. Os critérios de inclusão para a participação foram: 1) a criança ter entre cinco e 12 anos de idade; 2) estar matriculada no Ensino Fundamental em escola pública ou privada; 4) ter o consentimento livre e/ou esclarecido dos responsáveis legais para a participação na pesquisa e 5) ter o assentimento verbal e escrito da criança para participar da pesquisa.

Dentre as crianças, $88(81,5 \%)$ estudam em escolas privadas filantrópicas e $20(18,5 \%)$ em escolas públicas da cidade do Rio de Janeiro. Conforme informações declaradas pelos responsáveis, a maioria das crianças residia nas comunidades da zona sul do Rio de Janeiro, eram oriundas de famílias católicas e evangélicas, com renda familiar entre 1 a 3 salários mínimos (Tabela 1). Além das crianças, participaram também seus responsáveis, sendo 77 mães $(71,3 \% ; M$ idade $=36,9 ; D P=7,31)$ e 24 pais $(22,2 \% ; M$ idade $=41,7 ; D P=$ $9,1)$. 
Tabela 1

Dados Sociodemográficos da Amostra

\begin{tabular}{|c|c|c|}
\hline \multirow[b]{2}{*}{ Idade } & \multicolumn{2}{|c|}{ Total } \\
\hline & $M$ & $D P$ \\
\hline & 8,58 & 1,54 \\
\hline Faixa etária & $N$ & $\%$ \\
\hline 5 anos & 2 & 1,9 \\
\hline 6 anos & 7 & 6,5 \\
\hline 7 anos & 19 & 17,6 \\
\hline 8 anos & 25 & 23,1 \\
\hline 9 anos & 20 & 18,5 \\
\hline 10 anos & 26 & 24 \\
\hline 11 anos & 6 & 5,6 \\
\hline 12 anos & 3 & 2,8 \\
\hline Gênero & $N$ & $\%$ \\
\hline Masculino & 57 & 52,8 \\
\hline Feminino & 51 & 47,2 \\
\hline Zonas do Rio de Janeiro & $N$ & $\%$ \\
\hline Sul & 79 & 74,3 \\
\hline Norte & 24 & 21 \\
\hline Central & 1 & 0,9 \\
\hline Oeste & 3 & 2,7 \\
\hline Rural & 1 & 0,9 \\
\hline Renda familiar mensal & $N$ & $\%$ \\
\hline Sem renda & 7 & 6,5 \\
\hline Até 1 salário mínimo & 34 & 31,5 \\
\hline De 1 a 3 salários mínimos & 55 & 50,9 \\
\hline Sem especificação & 7 & 6,5 \\
\hline De 3 a 5 salários mínimos & 3 & 2,8 \\
\hline De 5 a 8 salários mínimos & 1 & 0,9 \\
\hline Mais de 8 salários mínimos & 1 & 0,9 \\
\hline Religião & $N$ & $\%$ \\
\hline Católica & 52 & 48,3 \\
\hline Evangélica & 32 & 29,6 \\
\hline Católica e evangélica & 8 & 7,4 \\
\hline Sem religião & 8 & 7,4 \\
\hline Sem especificação & 4 & 3,7 \\
\hline Espírita & 1 & 0,9 \\
\hline Sincretista & 1 & 0,9 \\
\hline Católica, umbandista e evangélica & 1 & 0,9 \\
\hline Católica, espírita e evangélica & 1 & 0,9 \\
\hline Composição das famílias & $N$ & $\%$ \\
\hline Casal com filhos & 60 & 55,6 \\
\hline Monoparental feminina & 18 & 16,7 \\
\hline Casal com filhos e parentes & 9 & 8,3 \\
\hline Reconstituída & 9 & 8,3 \\
\hline Mãe com filhos e parentes & 6 & 5,6 \\
\hline Estendida & 2 & 1,9 \\
\hline Monoparental masculina & 2 & 1,9 \\
\hline Homoafetiva feminina & 1 & 0,9 \\
\hline Pai com filhos e parentes & 1 & 0,9 \\
\hline
\end{tabular}




\section{Instrumentos}

Desenho da família. Foi solicitado à criança que realizasse o desenho de uma família a partir do seguinte rapport: "Gostaria que você desenhasse uma família". Para isso, a criança recebia uma folha de papel A4, lápis preto n.2 e coloridos, borracha e apontador. A tarefa foi realizada sem delimitação de tempo e nenhuma outra instrução ou informação foi fornecida à criança de modo a evitar qualquer viés na escolha e execução do desenho.

Formulário de Registro do Desenho da Família. trata-se de uma ficha para registro das informações sobre como o desenho foi realizado pela criança. Enquanto a criança desenhava, a pesquisadora tomava notas sobre a ordem dos personagens desenhados. Ao fim da execução do desenho, foram realizadas perguntas à criança de modo a compreender as características do desenho realizado.

Questionário sociodemográfico. Foi enviado aos responsáveis um questionário com perguntas fechadas e abertas sobre características familiares, como dados relacionados à ordem de filhos, indivíduos que residem com a criança, quais as pessoas, que filhos convivem com frequência, dados econômicos, presença e/ou ausência de religião e de membros homoafetivos na família, entre outros.

\section{Procedimentos Éticos e de Coleta de Dados}

Esta pesquisa seguiu todas as recomendações éticas propostas na Resolução 510/2016 (Conselho Nacional de Saúde [CNS], 2016). O projeto foi aprovado pela Plataforma Brasil (CAEE $80702517.1 .0000 .8144)$. Inicialmente foi realizado o contato com escolas apresentando os objetivos e o método da pesquisa. A escolha dessas escolas aconteceu por conveniência, devido ao acesso facilitado às instituições que já atuam como parceiras do laboratório de pesquisa. Em cada uma das escolas foi entregue uma cópia resumida do projeto de pesquisa, uma carta de apresentação da pesquisa e uma carta de aceite, a qual foi assinada pelo(a) responsável da escola e devolvida à pesquisadora.

Para as escolas que aceitaram participar do estudo, foram realizados os seguintes procedimentos: 1) Reunião com os responsáveis para a explicação da pesquisa, assinatura do Termo de Consentimento Livre e Esclarecido (TCLE) e preenchimento do questionário sociodemográfico, 2) Apresentação da pesquisa às crianças cujos TCLE foram devidamente assinados e devolvidos, 3) Assinatura do Termo de Assentimento Livre e Esclarecido, 4) Realização da coleta de dados com as crianças que assentiram participar da pesquisa.

A solicitação às crianças ocorreu da seguinte maneira: "Eu gostaria que você desenhasse nessa folha uma família". Foram disponibilizados lápis preto $\mathrm{n}$. 2, lápis coloridos borracha e apontador. 
Conforme já mencionado, o desenho foi realizado sem delimitação de tempo e nenhuma outra instrução ou informação foi fornecida à criança de modo a evitar qualquer viés na escolha e execução do desenho. Além disso, foi facultada à criança a realização do desenho cromático ou acromático. Após a conclusão da tarefa, foram solicitados esclarecimentos sobre as seguintes características dos desenhos: quem eram os membros desenhados e quais suas características (membros próximos e distantes, maiores e menores, com mais e menos detalhes), como era o espaço ocupado pela família (lugar, período específico do ano, tempo no desenho), quais os comportamentos e sentimentos das pessoas desenhadas (como estão se comportando e se sentindo individualmente e em conjunto). Tais informações foram fornecidas verbalmente pelas crianças e da mesma forma não houve delimitação de tempo para as respostas. Todas as informações foram registradas, pela pesquisadora, no Formulário de Registro do Desenho da Família, para posterior análise.

\section{Procedimentos de Análise de Dados}

Todos os desenhos foram recolhidos, identificados e armazenados em pastas devidamente identificadas. Os desenhos e informações registradas no formulário de registro foram analisados individualmente e classificados a partir de quatro categorias definidas a priori. Essas categorias foram escolhidas com base em estudos sobre desenho de família (Wagner e Bandeira, 1996; Wagner \& Féres-Carneiro, 2000). No entanto, serão apresentadas e discutidas de maneira descritiva e com base na teoria da análise do comportamento:

1) Composição familiar: foi descrito quem compõe o desenho da família como, por exemplo: mãe e filhos; pai e filhos; mãe, pai e filhos; família extensiva (família nuclear, parentes, avós, tios e primos), família extensiva ampliada (parentes, amigos, babá) e família extensiva ampliada incluindo animais domésticos (cães, gatos, entre outros).

2) Configuração do espaço geográfico: foi informado o local em que a família estava situada no momento registrado no desenho e o tempo representado no desenho (e.g., dia das crianças/aniversário da criança/férias, tempo quente/frio/meio termo).

3) Nível de conteúdo: foram registrados dados quanto à valorização dos membros da família (mais próximo à criança, maior e com mais detalhes) e desvalorização dos membros da família (mais distante da criança, menor e com menos detalhes).

4) Dinâmica interacional da família: a criança indicou de que maneira se comportava cada um dos membros (e.g., ações realizadas no momento do desenho) e como cada um estava se sentindo. A criança mencionou, após a realização do desenho, se eles estavam realizando 
alguma atividade juntos, como se sentiam como grupo e se alguém ficou excluído da atividade e/ou foi esquecido de ser desenhado no momento do desenho.

Os dados categorizados pela pesquisadora, obtidos por meio do registro dos desenhos, bem como os dados do questionário sociodemográfico foram tabulados e analisados por meio do software estatístico IBM SPSS versão 22. Estatísticas descritivas foram conduzidas com o objetivo de descrever e resumir os dados sobre as famílias participantes (crianças e responsáveis). Para investigar a relação das variáveis "modalidade de família" e "inclusão de conviventes", "modalidade de família" e "representação de momentos coletivos", foi utilizado o teste qui-quadrado de Pearson. Especificamente, foram investigadas possíveis associações entre modalidades de famílias e vivência de momentos de afeto, modalidades de famílias e membros incluídos no desenho. O teste detectou a existência ou não de uma associação significativa entre tais variáveis.

\section{Resultados e Discussão}

Este estudo investigou de que forma as crianças cariocas representam graficamente as famílias, tomando como base a teoria da análise do comportamento. Os resultados serão apresentados e discutidos segundo as categorias de análise 'composição familiar', 'configuração do espaço geográfico', 'nível de conteúdo' e 'dinâmica interacional da família'.

\section{Composição Familiar}

Um dos resultados encontrados foi de que a maioria das crianças $(89,9 \%, n=97)$ optou por desenhar a própria família quando o comando era de que elas desenhassem uma família qualquer, sem nenhuma especificação. Em consonância com a literatura, esse dado sugere que 0 desenho pode ser uma ferramenta útil para compreender a relação da criança com sua própria realidade, incluindo seu próprio ambiente, no caso, sua família (Regra, 2001). Nesse sentido, quando a criança foi convidada a desenhar uma família, logo se remeteu à própria família, sentindo-se convidada a comunicar seus sentimentos e pensamentos em relação à família de origem (Figueiredo \& Naves, 2018).

Mesmo que o cenário familiar atual seja marcado por múltiplas configurações de famílias, e não por única versão de família formada por casais heterossexuais com filhos (IBGE, 2014), apenas uma parte pequena da amostra $(32,3 \% ; n=35)$ representou outras modalidades de famílias, como família ampliada, monoparental feminina e 
masculina, casal e filhos com animais domésticos e/ou amigos, reconstituída, entre outros (Tabela 2 ).

Tabela 2

\begin{tabular}{lcc} 
Modelos de Famílias no Desenho da Família & & \\
\hline Modalidades & 73 & $\% 7,7$ \\
\hline Casal com filhos & 7 & 6,5 \\
Família estendida & 5 & 4,6 \\
Casal e filhos com parentes & 4 & 3,7 \\
Familia estendida com amigo(s) & 3 & 2,8 \\
Família estendida com animais domésticos & & \\
Irmão(s) & 3 & 2,8 \\
Monoparental feminina & 3 & 2,8 \\
Familia reconstituída & 2 & 1,9 \\
Casal e filhos com animais domésticos & 1 & 0,9 \\
Casal (mulher e homem) & 1 & 0,9 \\
Criança & 1 & 0,9 \\
Familia de animais & 1 & 0,9 \\
Filho & 1 & 0,9 \\
Mãe & 1 & 0,9 \\
Monoparental masculina & 1 & 0,9 \\
Primo & 108 & 100 \\
Total & &
\end{tabular}

A maioria dos participantes da amostra total desenhou famílias compostas por casal heterossexual e filhos $(67,6 \%, n=73)$, ainda que não fosse esse o modelo de família em que estivesse inserido. A pesquisa de Ribeiro e Cruz (2013), a qual investigou representações de famílias para crianças da cidade de Recife (PE), por meio do desenho de família, corrobora tais achados. Um dos resultados em comum foi de que as crianças representaram famílias compostas predominantemente por pai (sexo masculino) e mãe (sexo feminino) com filhos. Os autores concluíram que as famílias foram representadas de maneira idealizada e afetiva. Além disso, perceberam uma tensão entre um sentido conservador e uma perspectiva mais abrangente marcada pelo afeto. No presente estudo, 58,3\% $(n=63)$ das crianças desenharam famílias diferentes da constituição de sua família real. Quando a criança desenha uma família não correspondente ao seu modelo em vigência ou quando reproduz um modelo de família tradicional, pode estar demonstrando suas expectativas em relação a como deveria se configurar uma família. A família desenhada pode ser, nesse sentido, idealizada, ou seja, não está necessariamente de acordo com a família que se tem realmente, mas pode estar associada à família que gostaria de ter. Neste estudo, $65 \% \quad(n=13)$ das crianças oriundas de famílias monoparentais desenharam famílias tradicionais compostas por pai, mãe e filhos. 
Para Skinner (1981), regras são descrições entre ações e consequências por meio de instruções, leis ou conselhos. Na sociedade atual há a regra (leis) que garante a legitimidade de uma família por meio de outras uniões (e.g., genitor sozinho com crianças, famílias reconstituídas e/ou homoafetivas) sem que se cogite apenas o modelo de família formada por um casamento entre homem e mulher com filhos. No entanto, ainda sobrevivem conceitos (e.g., religiosos, morais) que entendem outras configurações familiares como menos naturais ou "esperadas" em relação às tradicionais. Essas concepções (antigas e atuais) concorrem entre si (Skinner, 2003/1953). Uma vez que o cuidador tenha a regra de que família é formada por homem e mulher, pode verbalizar para o filho que uma família é formada por mulher e homem por meio do casamento ou não. A escola, por sua vez, pode convocar apenas mães (mulheres) em comemorações ao dia das mães, sem averiguar se a criança conta com a presença dessa figura em sua vida. Em instâncias midiáticas e religiosas também é propagada a regra de que a família deve ser formada por mulher e homem, seja por meio do discurso verbal ou até mesmo pelo uso de imagens (e.g., em comerciais) que estampem famílias tidas como 'margarinas' (Alcântara, Peixoto, \& Silva, 2017). Dito isso, entende-se que a perspectiva de família heteronormativa, representada nos desenhos do presente estudo pode ter relação com o perfil da amostra, já que grande parte das crianças era proveniente de famílias religiosas $(88,9 \%, n=96)$, segundo informação fornecida pelos cuidadores.

As concepções tradicionais de famílias podem ser mais facilmente difundidas no meio religioso (Dias, 2017). Essas regras podem estar embutidas na escolha por determinada programação na televisão, nos conteúdos discutidos em casa e na escola (e.g., percepções sobre famílias e mundo). Assim como no presente estudo, uma pesquisa conduzida por Et e Memis (2017) enfatizou a percepção de crianças norte-americanas sobre a figura do cientista por meio do desenho. Apesar de se tratar de outro objetivo (no caso, representar o cientista), as crianças de cinco a 12 anos de idade, mesma faixa etária da amostra dessa pesquisa, também representaram uma versão do cientista possivelmente impactada pela mídia, uma vez que a maior parte deles foram representados por homens (e.g., é comum a expressão "homens da ciência" em vez de "cientistas" no contexto das mesmas) com características físicas representadas em filmes e/ou desenhos (e.g., roupas como jalecos, acessórios de laboratórios, óculos, entre outros).

Por outro lado, uma vez que uma família é constituída por indivíduos os quais não convivem e/ou residem juntos, conforme a representação gráfica das crianças amostrais, sugere-se uma concepção de que família é representada, sobretudo, por vínculos afetivos (Ribeiro \& Cruz, 2013). Esses vínculos afetivos podem ser 
mantidos pela convivência familiar, tal qual preconizado pela Constituição da República Federativa (Brasil, 1988) e pelo Estatuto da Criança e do Adolescente (Lei n. 8069, 1990). As legislações asseguram o direito de a criança conviver com a família, incluindo a família extensiva e ambos os genitores em condições pós-divórcio (e.g., Artigo 19, ver em Lei n. 8069, 1990). As frequências de contato com familiares podem ser cotidianas ou intermitentes. A convivência próxima pode facilitar um estreitamento de laços ou funcionar como uma fonte de conflito e promover distanciamento (Soares, Souza \& Cardoso, 2015). Nesse sentido, a simples presença de um genitor ou qualquer membro da família pode evocar respostas que garantam à criança o recebimento de atenção e do olhar do outro, ainda que se trate de uma relação familiar conflituosa. Em contrapartida, quando a convivência acontece com baixa frequência, a distância pode promover encontros esporádicos pontuais e oferecer justificativa para a falta de vínculo entre indivíduos (Soares, Souza \& Cardoso, 2015). Por isso, quanto mais privada da presença de um determinado membro, maiores podem ser as chances de a criança verbalizar sobre o membro, inclusive por meio de desenhos.

$\mathrm{Na}$ amostra do presente estudo, $50 \%(n=9)$ das crianças construídas por famílias monoparentais femininas desenharam a família composta por mãe e filhos, sinalizando uma possível maior aceitação das modificações de configurações familiares. As crianças da amostra monoparental masculina permaneceram reproduzindo o modelo formado pai, mãe e filho(a) de maneira integral. Tal dado pode ser explicado pelo fato de que, no Brasil, a maioria dos filhos permanecem residindo com a mãe após a separação dos genitores (Instituto Brasileiro de Geografia e Estatística [IBGE], 2014), o que pode facilitar um afastamento paterno físico natural após a separação. Autores como Castillo (2010) consideram que pais de baixa e média renda, similar à amostra presente, afastam-se mais dos filhos pós-divórcio no quesito apoio afetivo e financeiro em virtude dos modelos monoparentais femininos ainda serem maioria, e não modelos de compartilhamento de guarda. Entende-se que, uma vez que a mulher detenha a guarda exclusiva, pode vir a envolver-se com mais propriedade nos cuidados e educação das crianças. Nesse sentido, além das concepções de gênero quanto aos cuidados básicos, o distanciamento financeiro e o provimento também conduzem à minimização da responsabilidade e vínculos afetivos/interacionais de pais em relação aos filhos (Juras \& Costa, 2016).

\section{Configuração do Espaço Geográfico}

A maior parte das crianças optou por desenhar as famílias ocupando espaços públicos $(67,6 \% ; n=74)$, e não privados (e.g., casa própria 
ou de algum parente, $32,4 \% ; n=34$ ). Até mesmo em relação às crianças que informaram que a família estava localizada em uma casa, apenas $17(43,6 \%)$ representaram graficamente uma casa física. A ênfase nos ambientes públicos pode acontecer em virtude de tais crianças fazerem parte de famílias de classes socioeconômicas menos privilegiadas, as quais residem mais próximas às ruas e/ou em maior contato com a situação de rua, uma vez que ocupavam espaços situados em morros e/ou comunidades localizadas no Rio de Janeiro. Condições físicas da casa também influenciam na perspectiva da rua como extensão do lar. Moradias quentes, desconfortáveis e reduzidas podem influenciar que famílias passem períodos do tempo na rua e compartilhem maior apanhado de experiências com a comunidade (Amazonas, Damasceno, Terto, \& Silva, 2003).

O estudo de Silva e Avelar (2014) teve como objetivo averiguar concepções de famílias para crianças recifenses em situação de rua, utilizando como uma das técnicas o desenho da família. Nessa amostra, a vulnerabilidade foi um dos aspectos considerado na compreensão dos vínculos familiares. As autoras concluíram que as crianças terminam por fazer da rua a extensão de sua casa, na medida em que a rua aparece como meio para alcançar um objetivo, sendo esse o de sobreviver. Com isso, os modelos familiares situados no contexto de um lar fisicamente representado foram enfraquecidos. $\mathrm{Na}$ presente pesquisa não houve uma amostra de crianças em situação de rua ou abandono, mas contemplou famílias vivendo em comunidades periféricas do Rio de Janeiro, o que pode corroborar com apresentação de resultados semelhantes ao do estudo citado.

No presente estudo, os participantes também foram questionados se a família do desenho estava em um dia especial. Diante da pergunta, $28,7 \%(n=31)$ das crianças mencionaram que não, enquanto outras mencionaram dias relacionados à presença da família reunida (e.g., o dia de união da família, casamento dos pais, dia em família, dia de felicidade em família, dia do abraço, dia em que mãe namora o pai e dia em que todos comem juntos, entre outros). Os resultados da análise de verossimilhança, opcional ao teste qui-quadrado, demonstrou que crianças de grupos de famílias tradicionais demonstraram 0,17 mais chances de evidenciar situações que evoquem momentos coletivos em família e com sinais de afeto quando comparadas às crianças de outros grupos familiares $\left(x^{2}(1)=11,23,(p=0,001)\right.$. A presença de genitores pode sinalizar um espaço mais propício para que crianças vivenciem momentos de recebimento de carinho, atenção e afeto (Skinner, 1989; Weber, 2017). 


\section{Nível de Conteúdo}

O membro representado em maior tamanho nos desenhos foi o pai $(42,5 \% ; n=45)$. Tal dado pode estar associado à estatura real do pai que, na maioria das vezes é mais alto que os demais membros. No entanto, uma discussão sobre gênero também pode ser retomada. No que tange à análise do comportamento, gênero é um termo relacionado à diferenciação social e cultural entre homens e mulheres (Heywood, 2010). Gênero pode ser visto com um conjunto de padrões de comportamentos ontogenéticos, ou seja, encarados como típicos de mulheres e homens dentro de uma cultura (Silva \& Laurenti, 2016). Ainda que as mulheres sejam provedoras de determinadas famílias e tenham ganhado destaque no mundo do trabalho, o homem ainda pode ser visto como figura de autoridade dada a história ontogenética e cultural (Alcântara et al., 2017). Tal realidade, ainda presente na sociedade ocidental, pode explicar, mesmo que em parte os dados do presente estudo.

O pai apareceu como o membro retratado na parte externa da folha, ou seja, mais distante $(25,9 \% ; n=28)$ ou isolado $(9,3 \% ; n=10)$ mesmo em famílias de casais com filhos. Isso pode refletir, ainda, 0 distanciamento desses pais, os quais, culturalmente, nem sempre executam a tarefa de cuidados com tanta disponibilidade como as mães em famílias de casais com filhos ou monoparentais (Silva \&Laurenti, 2016). Por outro lado, o personagem que apareceu mais perto da criança foi a mãe, mesmo no caso das crianças provenientes de famílias monoparentais masculinas. Uma hipótese a ser levantada é a de que, culturalmente, espera-se que os cuidados básicos (e.g., nutrição, aconchego, estabelecimento de rotina, higiene) para o desenvolvimento da criança sejam provenientes do gênero feminino (Alcântara et al., 2017). Esse dado de maior proximidade com as mães também vai ao encontro da literatura, a qual infere que até mesmo mães que não residem com os filhos exercem papel mais ativo na educação de seus filhos em relação aos pais que não coabitam com filhos (Greene, Anderson, Forgatch, Degarmo, \& Hetherington, 2012).

Vale destacar, ainda, que não houve uma associação entre membros retratados no desenho e membros que residem com as crianças participantes $\left(X^{2}(1)=10,5, p=0,72\right)$ e tampouco uma associação entre distanciamento e residência próxima à criança da amostra $\left(X^{2}(1)=18,9, p=0,39\right)$. Isso pode sugerir que noções de aproximação e/ou distanciamento, bem como de isolamento não têm relação direta com a coabitação, mais uma vez corroborando a ideia de que a proximidade é percebida muito mais pelo afeto que ela presença física (Ribeiro \& Cruz, 2013). 


\section{Dinâmica Interacional da Família}

As crianças enfatizaram nos desenhos, principalmente, as ações realizadas sozinhas, como mexer no celular, ver televisão, plantar, dormir, estudar, pensar (Tabela 3). Isso pode estar relacionado à cultura da sociedade contemporânea, que realça valores de liberdade e individualidade (Dias, 2017) e que enaltecem indivíduos sozinhos, com diminuída interação, características comuns aos grupos culturais em vigência (Skinner, 1989).

Tabela 3

Comportamentos Individuais no Desenho da Familia

\begin{tabular}{lcccccc}
\hline Comportamentos & \multicolumn{2}{c}{ Mãe } & \multicolumn{3}{c}{ Pai } & \multicolumn{3}{c}{ Criança } \\
\hline & $N$ & $\%$ & $N$ & $\%$ & $N$ & $\%$ \\
Atividades com criança & 24 & 21,6 & 27 & 24,3 & - & - \\
Atividades com mãe & - & - & 13 & 11,7 & 9 & 8,1 \\
Atividades com pai & 11 & 10 & - & - & 5 & 4,5 \\
Atividades com pais & - & - & - & - & 6 & 5,4 \\
Atividades com irmão(s) & 4 & 3,6 & 1 & 0,9 & 7 & 6,3 \\
Atividades sozinho(a) & 23 & 20,7 & 33 & 29,7 & 31 & 27,9 \\
Atividades coletivas & 11 & 9,9 & 7 & 6,3 & 9 & 8,1 \\
Atividades domésticas & 7 & 6,3 & 2 & 1,8 & 3 & 2,7 \\
Ausência de & 8 & 7,2 & 9 & 8,1 & 6 & 5,4 \\
comportamentos & & & & & & \\
\hline
\end{tabular}

Questões referentes ao gênero também apareceram nos resultados dos comportamentos dos membros das famílias. Percebe-se que para as crianças da amostra o homem ainda pode ser visto como o responsável por prover a casa em termos materiais, mas não por cuidar da rotina doméstica (Silva \& Laurenti, 2016). Uma das demonstrações de que essa concepção permanece é que parte das crianças $(29,7 \% ; n=33)$ referiu terem desenhados os pais trabalhando, dirigindo, ajudando a mãe, entre outros, reforçando a concepção de que os homens permanecem somente na função de cooperadores de cuidados a serem realizados por mulheres (Heywood, 2010; Silva \& Laurenti, 2016).

Além do questionamento sobre o que fazia cada personagem representado no desenho de maneira individual e coletiva, foi perguntado como cada personagem estava se sentindo naquele momento (Tabela 4). Os resultados sugerem que emoções positivas, como "bem", "feliz", "alegre", foram predominantes. As crianças também responderam como os personagens se sentiam por estarem juntos. As respostas mais frequentes foram felizes $(34,3 \% ; n=37)$ e "sentindo-se bem" $(28,7 \% ; n=31)$. 
Tabela 4

Sentimentos da Família e seus membros no Desenho da Família

\begin{tabular}{|c|c|c|c|c|c|c|c|c|}
\hline \multirow[t]{2}{*}{ Familia } & & & \multicolumn{2}{|c|}{ Mãe } & \multicolumn{2}{|c|}{ Pai } & \multicolumn{2}{|c|}{ Criança } \\
\hline & $N$ & $\%$ & $N$ & $\%$ & $N$ & $\%$ & $N$ & $\%$ \\
\hline Bem & 31 & 28,7 & 37 & 34,3 & 38 & 35,2 & 37 & 34,3 \\
\hline Feliz & 37 & 34,3 & 37 & 34,3 & 35 & 32,4 & 43 & 39,0 \\
\hline Alegre & 3 & 2,8 & 8 & 7,4 & 6 & 5,2 & 9 & 8,3 \\
\hline Nada & 9 & 8,3 & 2 & 1,9 & 3 & 2,8 & 2 & 1,9 \\
\hline
\end{tabular}

Para a análise do comportamento, emoção não se refere a um estado de consciência, e sim a uma alteração na predisposição à ação ou a um conjunto de respostas específicas (classes de respostas) (Skinner, 2003/1953). As crianças, de maneira geral, descreveram verbalmente sentimentos como bem, legal, nada, feliz, entre outros. Isso pode representar uma maneira de falar sobre sentimentos com uma descrição comprometida ou ausente, sugerindo ocorrência de um operante verbal intraverbal. Respostas intraverbais são consideradas por Skinner (1957) como triviais ou fórmulas usadas socialmente de maneira automática. Comumente, quando indivíduos são questionados "Como vai você?", podem responder de maneira automática "bem", sem que se reflita e descreva após a pergunta. Nesse sentido, nessa pesquisa, quando foi perguntado às crianças "Como determinado membro está se sentindo no desenho?", elas podem ter emitido respostas intraverbais sem que fique claro como, de fato, os membros do desenho estivessem se sentido.

Quanto à inclusão e exclusão de membros nas atividades da família, o pai foi o membro mais incluído mesmo nos casos em que a criança reportou não coabitar com o pai. Ele foi incluído em maior proporção por crianças de famílias monoparentais femininas $(50 \% ; n=9)$ e mãe com filhos e parentes $(50 \% ; n=3)$. O teste qui-quadrado indicou que houve uma associação significativa entre o tipo de modalidade de famílias não tradicionais (que não incluíam o pai) e a inclusão da figura paterna em maior tamanho no desenho, $X^{2}(30)=75,3$ $(p=0,001)$. Isso sugere que crianças que não coabitam com os pais estão sensíveis à presença do mesmo e à sua importância na configuração familiar. Pode-se sugerir a existência de uma privação de contato e de atenção relacionada à presença do genitor com o qual não coabita. A ausência do genitor aumenta, com isso, o valor dos reforçadores envolvidos em estar com o pai (e.g., ser cuidado, sentir-se olhado, ter companhia, ter alguém a suprir necessidades, entre outros), por isso, diz-se tratar de uma operação motivadora (Skinner, 2003/1953). 


\section{Considerações Finais}

O presente estudo teve como objetivo investigar de que forma as crianças cariocas representam graficamente as famílias, tomando como base a teoria da análise do comportamento. Essa teoria indica que a constituição de famílias é produto de transformações históricas e culturais. Concepções de famílias variam conforme o nível cultural em que o indivíduo está inserido (Silva \& Avelar, 2014). No presente estudo, em virtude de as crianças participantes serem em maior parte proveniente de famílias de casal heteroafetivo com filhos e de educação religiosa, o valor da tradição pode ter maior destaque. Isso pode explicar os desenhos de famílias da amostra serem, em maioria, representados por um casal composto por homem, mulher $\mathrm{e}$ criança(s).

Além disso, o conservadorismo relacionado aos papéis e funções de gênero na família e na sociedade também foram identificados nesse estudo. As crianças enalteceram a concepção de pai e marido como provedor e de mãe e esposa como cuidadora da casa e das tarefas relacionadas aos filhos. Isso aparece como contraponto das regras atuais que gerem a sociedade, em que discursos e leis enaltecem uma igualdade entre tarefas e gênero (Silva \& Laurenti, 2016). No entanto, na prática, as contingências ainda precisam ser modificadas de maneira que homens e mulheres possam conviver compartilhando tarefas, optando por arranjos de famílias que desejarem e viverem deixando, de fato, a dimensão do afeto já apontada pelas crianças da amostra ser o principal fator que os une na vida em grupo. Chama a atenção o fato dos membros que residem com as crianças não terem sido considerados, necessariamente, como constituintes das famílias. A noção de família para as crianças do presente estudo teve, sobretudo, maior relação com a função que ela exerce no desenvolvimento da criança, representando fonte de amor, suporte emocional e/ou material.

O estudo apresentou algumas limitações, como a amostra restrita de crianças da cidade do Rio de Janeiro. Uma amostra mais diversificada poderia incluir grupos de crianças de outros contextos regionais, com condições socioeconômicas, religiões e configurações familiares variadas. Além disso, os poucos estudos empíricos sobre o desenho da família são predominantemente de orientação psicodinâmica, o que dificultou a discussão dos resultados a partir dos pressupostos da análise do comportamento ou, ainda, de outras teorias comportamentais.

Esse estudo trouxe contribuições originais, pois propôs novas perspectivas empíricas e teóricas para a avaliação do desenho da família com foco na descrição de elementos trazidos no desenho. Além disso, demonstrou como que crianças manifestam o que sentem por meio do desenho da família, bem como que noções de famílias do 
ponto de vista do afeto têm soberano destaque na atualidade. Atenta-se, ainda, para a necessidade de que novos estudos avancem na concepção de como os diversos arranjos familiares são compreendidos pelas crianças atualmente, incluindo as discussões sobre papéis de gênero e relevância do trabalho sobre expressão de sentimentos e configurações de comportamentos em grupo já apontadas inicialmente nesse estudo.

\section{Referências}

Alcântara, P. P. T., Peixoto, C. L., \& Silva, A. M. S. (2017). As relações patriarcais de gênero na família: Influência da mídia televisiva. HOLOS, 33(7), 270-277. doi: $10.15628 /$ holos.2017.5436

Amazonas, M. C. L. A., Damasceno, P. R., Terto, L. M. S., \& Silva, R. R. (2003). Arranjos familiares de crianças das camadas populares. Psicologia em Estudo, 8(spe), 11-20. doi:10.1590/S1413-73722003000300003

Bijou, S. W., \& Latham, G. I. (2012). The Power of Positive Parenting: a wonderful way to raise the children. North Logan: P \& T Ink.

Brasil. (1988). Constituição da República Federativa do Brasil. Brasília, DF: Senado Federal. Recuperado de http://www.senado.gov.br/sf/legislacao/const/

Brasil. (1990). Lei n. 8.069, de 13 de julho de 1990. Estabelece o Estatuto da Criança e do Adolescente. Brasília, DF: Diário Oficial da União.

Castillo, J. T. (2010). The relationship between non-resident fathers' social networks and social capital and the establishment of paternity. Child and Adolescent Social WorkJournal, 27(3), 193211. doi:10.1007/s10560-010-0202-0

Conselho Nacional de Saúde [CNS]. (2016). Resolução no 510/2016 Dispõe sobre a pesquisa em Ciências Humanas e Sociais. Brasília, DF: Ministério da Saúde.

Dias, M. B. (2017). Manual de direito das famílias (12a ed.). São Paulo: Revista dos Tribunais.

Et, S. Z., \& Memis, E. K. (2017). The Perceptions of Five Years Old Group Students' about Scientists. Journal of Education and Training Studies, 5(2), 140-148. doi:10.11114/jets.v5i2.2167

Figueiredo, C., \& Naves, A. R. C. X. (2018). O uso do desenho na avaliação de repertórios comportamentais de crianças. In A. K. C. R., De-Farias, F. N., Fonseca, \& L. B., Nery (Orgs.), Teoria e formulação de casos em análise comportamental clínica (pp. 114-127). Porto Alegre: Artmed.

Greene, S. M., Anderson, E. R., Forgatch, M. S., Degarmo, D. S., \& Hetherington, E. M. (2012). Risk and resilience after divorce. In 
F. Walsh (Org.), Normal Family Processes: Growing Diversity and Complexity (pp. 102-127). New York: The Guilford Press.

Heywood, A. (2010). Feminismo. In J. Marcoantonio, \& M. Janikan (Orgs.), Ideologias políticas: Do feminismo ao multiculturalismo (pp. 21-43). São Paulo: Ática.

Instituto Brasileiro de Geografia e Estatística [IBGE]. (2014). Estatísticas do Registro Civil: 2014. Rio de Janeiro: Ministério do Planejamento, Orçamento e Gestão.

Juras, M. M., \& Costa, L. F. (2016). Não foi bom pai, nem bom marido: conjugalidade e parentalidade em famílias separadas de baixa renda. Psicologia: Teoria e pesquisa, 32(spe), 1-9. doi:10.1590/0102-3772e32ne215

Naves, A. R. C. X., \& Vasconcelos, L. A. (2008). O estudo da família: Contingências e metacontingências. Revista Brasileira de Análise do Comportamento, 4(1), 13-25. doi: $10.18542 /$ rebac.v4i1.841

Regra, J. A. G. (2001). A fantasia infantil na prática clínica para diagnóstico e mudança comportamental. In R. C. Wielenska (Org.), Sobre comportamento e cognição: Questionando e ampliando a teoria e as intervenções clínicas e em outros contextos (pp. 179-186). Santo André: ESETEC.

Ribeiro, F. S., \& Cruz, F. M. L. (2013). Representações sociais de família por crianças na cidade de Recife. Psicologia \& Sociedade, 25(3), 612-622. doi:10.1590/S0102-71822013000300015

Rigg, A., \& Pryor, J. (2007). Children's perceptions of family: what do they really think? Children \& Society, 21(1), 17-30. doi:10.1111/j.1099-0860.2006.00028.x

Silva, E. C., \& Laurenti, C. B. F. (2016). B. F. Skinner e Simone de Beauvoir: "a mulher" à luz do modelo de seleção pelas consequências. Perspectivas em Análise do Comportamento, 7(2), 197-2011. doi:10.18761/pac.2016.009

Silva, J. M. M. S., \& Avelar, T. C. (2014). Crianças em situação de rua e suas representações lar e família por meio do desenho. Psicologia Argumento, 32(76), 69-77. doi:10.7213/psicol.argum.32.076.A003

Skinner, B. F. (1957). Verbal Behavior. New York: ApplentonCentury-Crofts.

Skinner, B. F. (1981). Selection by consequences. The Behavioral and Brain Sciences, 7(4), 477-510. doi: $10.1017 /$ S0140525X0002673X

Skinner, B. F. (1989). Recent Issues in the Analysis of Behavior. Columbus: Merril Publishing Company.

Skinner, B. F. (2003). Ciência e comportamento humano (11a ed.) São Paulo: Martins Fontes, 2003. (Obra original publicada em 1953). 
Soares, L. C. E. C. S., Souza, F. H. O., \& Cardoso, F. S. (2015). Convivência familiar em três cenários: Acolhimento institucional, famílias recasadas e violência doméstica. Psicologia Argumento, 330-345. doi:10.7213/psicol.argum.33.082.A001

Wagner, A., \& Bandeira, D. (1996). O desenho da família: Um estudo sobre adolescentes de famílias originais e reconstituídas. In $\mathrm{R}$. M. Macedo (Org.), Coletânea da ANPPEP: Família e Comunidade (pp. 115-126). São Paulo: Press Grafic.

Wagner, A., \& Feres-Carneiro, T. (2000). O recasamento e a representação gráfica da família. Temas em Psicologia, 8(1), 11-19. Recuperado de http://pepsic.bvsalud.org/scielo.php?script=sci_abstract\&pid=S 1413-389X2000000100002

Weber, L. (2017). Eduque com carinho para pais e filhos (6a ed.) Paraná: Juruá.

\section{Endereço para correspondência \\ Ilana Landim}

Pontifícia Universidade Católica do Rio de Janeiro - PUC-Rio

Programa de Pós-Graduação em Psicologia Clínica

Rua Marquês de São Vicente, 225, Gávea, CEP 22451-900, Rio de Janeiro - RJ, Brasil

Endereço eletrônico: ilanaclandim@gmail.com

\section{Juliane Callegaro Borsa}

Pontifícia Universidade Católica do Rio de Janeiro - PUC-Rio

Programa de Pós-Graduação em Psicologia Clínica

Rua Marquês de São Vicente, 225, Gávea, CEP 22451-900, Rio de Janeiro - RJ, Brasil

Endereço eletrônico: juliborsa@gmail.com

Recebido em: 10/09/2018

Reformulado em: 07/04/2019

Aceito em: 15/04/2019

\section{Notas}

* Mestre em Comunicação pela Universidade Federal do Ceará (UFC). Doutora em Psicologia Clínica pela Pontifícia Universidade Católica do Rio de Janeiro (PUC-Rio). Professora e Coordenadora de Pesquisa e Extensão do Curso de Psicologia do Centro Universitário Christus (Unichristus).

** Mestre em Psicologia Clínica pela Pontifícia Universidade Católica do Rio Grande do Sul (PUCRS). Doutora e pós-doutora em Psicologia pela Universidade Federal do Rio Grande do Sul (UFRGS). Professora Adjunta do Departamento de Psicologia e do Programa de Pós-Graduação em Psicologia Clínica da Pontifícia Universidade Católica do Rio de Janeiro (PUC-Rio).

Financiamento: Conselho Nacional de Desenvolvimento Científico e Tecnológico

Este artigo de revista Estudos e Pesquisas em Psicologia é licenciado sob uma Licença Creative Commons Atribuição-Não Comercial 3.0 Não Adaptada. 